\title{
Em Casa que Mulher Manda, até Galo Canta Fino: análise da construção midiática da personagem Dilma Rousseff
}

\author{
In Homes Headed by Women even Roosters Crow Low': the analysis of media \\ construction of Dilma Rousseff's character
}

\author{
João Gabriel Maracci Silveira Cardoso \\ Pontifícia Universidade Católica do Rio Grande do Sul - Brasil \\ jmaraccicardoso@gmail.com
}

\author{
João Pedro Cé \\ Pontifícia Universidade Católica do Rio Grande do Sul - Brasil \\ joaopedroce@yahoo.com.br
}

\section{Mariana Barcinski}

Pontifícia Universidade Católica do Rio Grande do Sul - Brasil

mbarcinski@gmail.com

\section{Adolfo Pizzinato}

Pontifícia Universidade Católica do Rio Grande do Sul - Brasil adolfo.pizzinato@pucrs.br

\section{Resumo}

Este artigo analisa a construção da personagem Dilma Rousseff em uma revista mensal brasileira. Discute-se o papel das relações de gênero na representação política, através da mídia e do marco cultural que a engloba. $O$ corpus de análise abrange 17 edições da coluna Diário da Dilma, presente na Revista Piauí. O método utilizado se vale do modelo de Ives Reuter para Análise da Narrativa, tendo como arcabouço ideológico as orientações dos Estudos Críticos do Discurso. Percebe-se que a posição de marginalização política feminina permanece, principalmente quando vinculada a expressões humorísticas, apesar da ascensão política das mulheres brasileiras.

Palavras-Chave: Papéis de Gênero; Política; Mídia.

\begin{abstract}
This study analyzes the construction of the literary character of Dilma Rousseff - by a monthly Brazilian magazine. We discuss the role of gender relationships in media representation, and the cultural landmark that surrounds this media. The data analyzed come from 17 editions of the magazine column called Diário da Dilma (Dilma's Diary), present in Revista Piauí (Piauí Magazine). The method adopted includes elements from both Critical Discourse Studies and the Narrative Analysis model created by Ives Reuter. We conclude that the media continue to display patterns that undermine female role in politics, particularly by associating women to expressions of futility, irresponsibility, and instability.
\end{abstract}

Keywords: Gender Roles; Policy, Media. 


\section{Introdução}

Este artigo analisa a construção da personagem Dilma Rousseff na coluna Diário da Dilma, publicada na revista mensal Piauí. A perspectiva adotada para a discussão focaliza os discursos presentes na cultura política brasileira e a relação que a mídia estabelece com a elaboração, legitimação e manutenção de estereótipos e papéis sociais através de seus posicionamentos, em especial os de gênero. Assim, sob a discussão de conceitos como gênero, mídia, estereótipos, processos de autoria e construção da personagem em uma perspectiva compatível com os Estudos Críticos do Discurso (ECD) (VAN DIJK, 2010), busca-se associar a análise linguística e a crítica social, considerando o momento sócio-histórico onde se produzem os discursos de uma personagem que se alicerça em tais conceitos. Tal associação dá-se através da perspectiva bakhtiniana (BAKHTIN, 2008) de entendimento e análise dos processos dialógicos envolvidos na construção de personagens e na manutenção de práticas culturais, enfatizando a ancoragem das práticas nas simbologias presentes na cultura, ao mesmo tempo em que a própria produção de símbolos é possível dentro de um contexto cultural específico.

Diferentemente das revistas convencionais do mercado editorial brasileiro, a Revista Piauí se propõe ao que alguns autores denominam de 'jornalismo literário' (SOUZA \& LIGÓRIO, 2012). Sua primeira edição foi lançada em outubro de 2006 e a revista costuma apresentar reportagens construídas a partir de estruturas narrativas de caráter ensaístico e não unicamente de fatos expositivos. Na análise de Juliana Lopes de Almeida Souza e Claudia Alice de Ligório, entende-se que a revista Piaú se define como:
(...) uma revista mensal de jornalismo, ideias e humor. Publicamos para quem gosta de ler. Vale praticamente qualquer tema. Política, literatura, economia, televisão, arquitetura, cinema, futebol, odontologia - contanto que o dentista seja interessante, ou o tratamento do canal, revolucionário (SOUZA \& LIGÓRIO, 2012, p. 163).

Considerando o caráter da publicação, a análise utilizada neste estudo preconiza a interpretação contextualizada dos textos, marcando seu caráter político e social como propõe as ideias dos ECD (VAN DIJK, 2010). Além disso, integram-se no presente estudo pressupostos da análise de narrativa (REUTER, 2010), articulando conceitos que possibilitam sistematizar a construção das personagens. Apontam-se, assim, os caracteres intra e extra-discursivos dos textos, colocando-os não como meras produções literárias em si, mas como simbolizações da realidade e artefatos culturais que revelam modos de ser e de produção das noções de sujeito. Por fim, é realizada uma reflexão acerca dos processos envolvidos na criação desses tipos de discurso, apontando a relação entre o processo de autoria e a criação de personagens como elementos importantes para entender as (re)produções dos estereótipos de gênero, especialmente da Personagem Dilma Roussef como uma mulher (na) política.

\section{Gênero, Estereótipos e Mídia}

Para definir de maneira relevante um conceito tão 'naturalizado' como o de gênero, é preciso que sejam considerados os locais ocupados pelos sujeitos e quais mecanismos identitários estão envolvidos no processo. Gênero refere-se às diferenciações socialmente construídas entre os sexos, mas não necessariamente diferenças anatômicas. 
Desta forma, reitera-se que o corpo biológico não pode ser a única fonte de explicação para que alguém se identifique, construa seu marco identitário de gênero, já que elementos socioculturais servem de ferramentas para significar as construções identitárias. A construção da noção de um Eu - Outro Alguém também é feita em um plano simbólico, não sendo apenas uma representação da realidade, mas uma elaboração dos elementos presentes na vida dos sujeitos e que são significados de uma forma ou outra no cotidiano e na sociedade atual "transformam um macho em homem e um fêmea em mulher" (STREY, 2001, p. 183). A linguagem e, portanto, os discursos que constroem as noções de sujeito, são de suma importância para caracterizar as identidades, uma vez que as formas de dizer quem se é usam ferramentas provenientes da cultura. Deste modo explicam-se comportamentos e escolhas feitas pelas pessoas e que as colocam assentadas ou movimentando-se sobre determinadas identidades (BRUNER, 1999).

As diferenciações entre os gêneros, por exemplo, são uma dessas dimensões identitárias discursivamente construídas. Essas diferenças são usualmente conceituadas sob a ótica reducionista do binarismo, relacionadas à dicotomia entre público esfera política, destinada exclusivamente aos homens - e privado - esfera doméstica, que relaciona a mulher à maternidade e ao lar -, (re)designando uma hierarquia do masculino sobre o feminino (ABOIM, 2012). As relações hierárquicas de gênero estruturam as noções de indivíduo e universalidade, que configuram a compreensão liberal da esfera pública a partir de uma percepção masculina dominante e que criam ou reproduzem marcadores identitários, que seriam próprios pra o âmbito público ou privado (BIROLI \& MELLO, 2010).
A subjugação das mulheres ao espaço privado refere-se, portanto, à exclusão do status público: nega-se à mulher o poder e a política na esfera da socialização. $O$ espaço doméstico, no entanto, não é desprovido de poder, possuindo recursos próprios para a marcação de hierarquias, que podem ser usados para a aquisição e reprodução do poder feminino (NEUHOUSER, 1986). Seria na preparação dos alimentos, cuidados com filhos e decisões acerca do âmbito doméstico que as mulheres exerceriam poder no espaço privado, estabelecendo relações de dependência e submissão com aqueles ao seu redor (COLLING, 2004). Entende-se, portanto, que o poder feminino seria acessível apenas a mulheres que desempenham um papel de feminilidade ideal - de acordo com a perspectiva masculina dominante: a boa mãe, boa esposa, etc., relacionado diretamente à marginalização feminina no âmbito público. A opressão feminina constitui-se como condição inseparável do conceito moderno de liberdade, que se mantém contemporâneo, afetando diretamente as identidades de gênero que organizam coletivos em nível micro e macro político.

$\mathrm{Na}$ análise das relações coletivas de identidade, a teoria da identidade social (TAJFEL, 1981) sugere que os diferentes coletivos sociais identificam-se devido à presença de outros grupos, pois é necessário que haja um movimento de diferenciação entre o que é Eu-Nós do que é Tu-Elas/Eles. Esse movimento de criação das identidades está embasado em marcadores que incluem ou excluem sujeitos de determinados grupos, criam noções de pertencimento e estão embasados em estereótipos presentes na cultura, dentre eles os de gênero.

Assim, os estereótipos são entendidos como marcadores, características ou construtos que auxiliam no processo de identificação (TAJFEL, 1981). Porém, mais 
do que categorias, tais estereótipos formam e direcionam significações carregadas de simbolismos onde os sujeitos e suas ações são interpretados por expectativas pré-existentes às situações sociais, balizando possibilidades identitárias e afirmando algumas atitudes e posicionamentos estabelecidos culturalmente (COLE, 1999). Aponta-se que o conceito de identidade social não evidencia que há consciência plena dos locais ocupados pelos indivíduos, mesmo que essa identidade esteja assentada em um sentimento de pertença ao grupo (PRADO, 2002). Por outro lado, assumir uma identidade política, por exemplo, é implicar-se no que tange aos direitos de determinado grupo e, portanto, acarretaria em uma consciência dos mecanismos de inclusão e exclusão social, nos quais se articulam tanto 'mobilidade' (supressão de diferenças entre classes) quanto 'movimentação social' (organização coletiva).

Assim, movimentam-se exclusões e discriminações que organizam as disparidades entre os grupos sociais e auxiliam a manter relações de poder, pois os estereótipos também servem como base para avaliação do que é normal ou desviante no comportamento das pessoas (BIROLI, 2010). Isto ocorre juntamente a um processo de naturalização, que acaba por não deixar brechas para o questionamento destas interpelações do real, ou seja, o processo de se exercer através de estereótipos é considerado como atividade subjetiva e passível ou não de escolhas (BIROLI, 2011). Olhar para a cultura e suas instituições é fundamental na compreensão dos modos como os seres humanos organizam e interpretam a realidade (BRUNER, 1997). O aparecimento do 'desviante' no cotidiano dos indivíduos parece ser sempre seguido de algum tipo de explicação, alguma forma de caracterizar e 'ajeitar' esse evento a determinada realidade. O inesperado passa, então, por uma explicação que foge aos estereótipos, surpreende por não estar 'encaixado' dentro deste padrão e, portanto, deve ser explicado, teorizado de alguma forma. Por mais que seja necessária a criação dessa explicação, ela só é possível dentro das ferramentas que a cultura dispõe para os indivíduos (BRUNER, 1997).

Construindo a teia de significações possíveis, os artefatos culturais também alimentam as ideias e são passíveis de manipulação, gerando novas vias de expressão. A mídia é um artefato altamente complexo nesse processo, pois exerce o poder de retroalimentar a criação de realidades e planos de significado, que se apresentam nos cotidianos através de roteiros (narrativos e comportamentais) conjugados aos esquemas (partes ordenadas em uma estrutura dinâmica que representam situações e objetos) (COLE, 1999). Funcionando como mecanismos de seleção, tais esquemas culturais auxiliam as pessoas a organizarem suas experiências de forma subjetiva e os roteiros definem espaços, pessoas, seus papéis sociais e, consequentemente, as ações apropriadas dentro de cada roteiro. Esses padrões são culturais e reforçam-se a cada vez que são executados e a apresentação deles no cotidiano possibilita que outros seres humanos desenvolvam-se dentro destas balizas, destes esquemas, através da linguagem (COLE, 1999).

Claudia Maria Finamore (2006), em relação aos 'esquemas de gênero', expõe que a mídia tem o papel de reconhecer os discursos vigentes e atua como um organismo dinâmico que acaba por também reconstruir, e não apenas reproduzir, os discursos vigentes sobre a vida das pessoas. No discurso midiático estão inseridos não só conceitos, mas uma série de elementos, tais como os afetos, imagens e signos construídos sobre determinadas situações. Assim, a referida autora afirma que as propagandas políticas e o que é veiculado/dito como conteúdo atrelado a pessoas públicas influenciam a 
construção do que a população acredita como sendo característica dos homens e mulheres presentes no exercício da política institucional, por exemplo (FINAMORE, 2006). Dessa forma, a realidade acessível através da mídia não é completa, mas sim um recorte, que direciona as possibilidades de interpretação do mundo social.

Apesar de o jornalismo ser usual e falaciosamente apresentado como uma atividade 'apolítica', neutra e preocupada com a factualidade da notícia, sua relação com a 'realidade dos fatos' passa, obrigatoriamente, pela mediação da consciência (esquemas e roteiros) daqueles que selecionam os discursos e imagens divulgadas (CASTELLS, 1999).

Considerando que uma preocupação chave da mídia em nosso modelo de sociedade é a manutenção de sua audiência, a credibilidade de suas informações é fundamental para capturar a atenção do público e, desta forma, o conteúdo divulgado deve ao mesmo tempo distanciar-se de um formato de opinião declarado, parcial e poder expressar aquilo que a própria cultura coloca como permitido dentro de valores políticos e morais básicos (CASTELLS, 1999). A mídia apresenta-se, desta forma, como um espaço de exercício e publicização da política, pois é através dela que a população obtém informações sobre os candidatos e governantes.

Cláudia Maria Finamore (2006), ao analisar propagandas políticas veiculadas na televisão, por exemplo, expõe noções e estereótipos vinculados às mulheres políticas, tais como a diferenciação entre a vida social/pública - associada ao mundo masculino - e a vida privada/doméstica vinculada à identidade de gênero feminina. Portanto, os espaços reservados aos homens são aqueles de prestígio social, apresentando homens carregados de idiossincrasias pessoais e profissionais, enquanto as mulheres possuem vinculação ao exercício da maternidade e ao cuidado do lar, mesmo quando se apresentam enquanto agentes públicos. Assim, as mulheres, para garantirem seu espaço no mundo da política institucional, necessitam apresentar (ou serem apresentadas como portadoras de) características de liderança e assertividade, ideias que na mídia tradicional (e no imaginário social) são vinculadas à identidade masculina. A masculinização, portanto, torna-se necessária para que se obtenha sucesso no exercício político. Mesmo assim, quando se lançam à política institucional, independentemente do grau de masculinização como é percebida a sua imagem, permanecem à margem das representações midiáticas.

Em estudo sobre a presença de mulheres políticas nas revistas semanais brasileiras, Flávia Biroli (2010) enfatiza a existência do panorama de masculinização e marginalização. Ao analisar a representação midiática das atuações das políticas de maior destaque - Heloísa Helena, Marta Suplicy e Dilma Rousseff - em comparação à representação do então ministro Márcio Thomaz Bastos, constata que as mulheres aparecem quantitativamente em menor número e que os homens ocupam posições mais centrais nas notícias, o que, segundo a autora, representa o local da mulher como marginal ou exterior ao campo da política (BIROLI, 2010). No mesmo sentido, ainda afirma que, qualitativamente, as revistas políticas vinculam as mulheres políticas aos espaços domésticos e os homens à vida pública e ao exercício da vida profissional. Vinculam ainda as mulheres às questões de apelo estético, ressaltando o cuidado com o próprio corpo, referindo dietas alimentares e sua vestimenta (BIROLI, 2010). Além disto, há também referência à personalidade de cada uma das candidatas estudadas, referindo características como afetividade e sensibilidade ao feminino e a imposição e 
firmeza como características masculinas e, portanto, estas mulheres importariam seu jeito 'durão' do mundo masculino.

Céli Regina Pinto (2005) aponta como a reserva a certos espaços (por vezes marginais na vida social), acaba não só por excluir os grupos das discussões políticas, mas também por impedir que pautas relacionadas às minorias sejam colocadas em jogo e discutidas como necessárias. Desta forma, intensificam a estratificação social, colocando não só os homens em um patamar de superioridade ao das mulheres, mas as classes socioeconômicas mais favorecidas no exercício do pleno poder sobre a sociedade, impedindo, assim, a mobilidade social. Corroborando essa ideia, Bohn (2006) refere que estas diferenciações também de locais a serem ocupados pelos diferentes agentes sociais impedem que a democracia seja exercida plenamente, uma vez que não há igualdade de oportunidade no exercício de poder para os distintos grupos.

Flávia Biroli (2011) apresenta ainda uma disparidade na perspectiva de diferentes tipos de mídia acerca das questões de gênero. Veículos tradicionais da informação, por seu caráter conservador e oligárquico, tendem a reforçar o padrão patriarcal marcado pela normatividade pelo masculino, opondo-se às tentativas de mudanças no paradigma da subordinação do feminino ao masculino. A mídia alternativa - que, a partir do processo de globalização e democratização da informação, amplia seu espaço e sua atuação -, tende, por sua vez, a apresentar progressismo em sua perspectiva, contestando o ideário vigente, ainda que não de maneira absoluta (BIROLI, 2011). O gênero feminino, sob a ótica desses blogs, jornais eletrônicos e periódicos de ideologia independente, segundo Flávia Biroli (2011), parece ter o potencial para transcender o plano privado e doméstico, uma vez que estes veículos possuem um caráter mais dinâmico e proativo, muitas vezes caracterizam as mulheres na política com força e legitimidade, ideais geralmente atribuídos ao gênero masculino, ainda que os resultados apresentados a seguir questionem esse caráter e essa apresentação do feminino na política.

Nessa mesma direção, Chris Barker (1999) aponta que as representações midiáticas das mulheres não necessariamente conferem com sua posição real ou potencial na sociedade, apresentando diferentes interpretações dos papéis sociais e criando 'imagens de mulher'. Essas imagens são estereótipos polarizados: situam-se entre a figura da 'mulher boa' passiva, submissa, sensível, domesticada - e da 'mulher má' - rebelde, independente, egoísta. É perceptível a relação entre a dualidade boa e má a dicotomia entre o público e privado, que legitima a opressão de gênero. Mais especificamente, o autor defende que os estereótipos femininos corriqueiros na mídia são: a 'rebelde' (masculinizada), a 'boa esposa' (doméstica, subordinada ao homem), a 'harpia' (agressiva, solteira), a 'cobra' (mentirosa, manipuladora), a 'vítima' (passiva, objeto de violência), a 'engodo' (aparentemente sem valor, mas forte na realidade), a 'sereia' (sensual, leva os homens à perdição), a 'cortesã' (frequentadora dos salões, cabarés, prostíbulos), a 'bruxa' (poderosa, mas subordinada ao homem) e a 'matriarca' (autoridade máxima de uma família, assexuada) (BARKER, 1999). Os estereótipos citados expressam o maniqueísmo: as 'mulheres boas' são atreladas ao plano privado, enquanto as 'más' são atreladas ao plano público. As figuras 'boas' da feminilidade são relacionadas a papéis de passividade e submissão - seguem a norma social -, enquanto as 'más' a papéis de autonomia - desviante da norma -, que colocaria em risco a estabilidade social e familiar.

Ambas as caracterizações estereotipadas 
coexistem nas diferentes formas de mídia política no que se refere a gênero, manifestando-se em pequenas marcações usualmente de tom humorístico. O humor, como afirma Woitowicz (2008), é julgado erroneamente como forma politicamente desideologizada de expressão, sendo desconsiderado o seu potencial significativo para a legitimação ou desconstrução de paradigmas estabelecidos. É notável, nas mais diferentes formas de mídia, a utilização de um humor conservador e sexista, que (re)produz e (re)afirma padrões vigentes de opressão, baseando-se em estereótipos e preconceitos.

Buscando compreender como tais elementos configuram a construção de uma personagem midiática, analisa-se a seguir como a revista Piauí 'cria' uma Dilma Rousseff e como essa personagem se relaciona com as representações de mulher (e) política ainda vigentes em nosso contexto cultural.

\section{Método}

Este artigo apresenta uma análise da coluna Diário da Dilma, publicada desde fevereiro de 2011 na revista mensal Piauí, produzida pela Editora Abril. Esta seção da revista propõe-se como um suposto diário pessoal da Presidenta, permeado por inferências humorísticas de sua vida pessoal e profissional, sendo escrita pelo ghost writer Renato Terra e ilustrada por Caco Galhardo. Ao total foram selecionadas dezessete edições da revista (das edições 53 a 69), nas quais 496 citações foram analisadas qualitativamente. A criação de códigos e categorias é amplamente utilizada nos processos de análise qualitativa dos discursos e, desta forma, apresentam-se palavras ou expressões que sintetizam os discursos, com o intuito de facilitar a apresentação das interpretações realizadas sobre o material coletado. Neste sentido, a partir do material trabalhado, foram geradas as seguintes categorias: 'frases populares'; 'estereótipos do feminino'; 'política' e 'personalidade da Dilma'. As quatro categorias foram entrelaçadas com o modelo de Ives Reuter (2007), apresentados acima através dos conceitos 'qualificação diferencial', 'autonomia diferencial', 'distribuição diferencial', 'pré-designação convencional', ‘comentário explícito' e 'personagem focalizadora'.

Para o entendimento da construção e reprodução desses mecanismos sociais de produção conceitual, parte-se aqui - além da leitura através da Psicologia Cultural - de uma aproximação metodológica aplicada ao viés dos Estudos Críticos do Discurso (ECD), tal como Teun Van Dijk (2010) postula. Tal formato de análise pressupõe uma preocupação dos pesquisadores em assumirem uma postura crítica em relação não só ao conteúdo do discurso, mas à produção dele enquanto ferramenta sóciopolítica. Desta forma, há a necessidade de entender os discursos não como fundamentos apenas para a prática acadêmica, mas como produções autoexplicativas, que revelam articulações subjetivas e posicionamentos culturais mais amplos. A ECD preocupa-se com a articulação entre os níveis macro (relações de gênero, disputas de poder entre ideologias, etc.) e micro sistêmicos (situação específica da produção discursiva). Essa articulação revela os modos como a cultura dispõe as ferramentas para organização das ideologias e quais tipos de ideais estão em jogo na produção do discurso. A análise de material discursivo, portanto, é pertinente para o entendimento dos processos sociais que criam, refutam ou corroboram com relações de poder, estereótipos, modelos de dominação e instituições sociais.

Há de se considerar na presente análise a construção da personagem enquanto um ser 
de identidade própria, independentemente de sua referente 'real', mas que possibilita com que os leitores identifiquem-se com suas características, ações e discursos. Sua interioridade acessada pelo leitor revela-se na construção da personagem, ou seja, a personagem coloca sobre o mundo sua visão e é esta visão que o leitor(a) ou autor(a) utiliza para compreender a própria personagem, suas ações e contextos. Desta forma, a criação de uma personagem é um movimento refratário: o autor ou autora, ao elaborar uma obra, tem seu olhar atravessado pela cultura e, consequentemente, sua personagem também modela essa visão, pois possui suas próprias concepções sobre a realidade, mesmo sendo uma consciência dentro da consciência do autor(a) (BAKHTIN, 2006). Há diversas formas de analisar uma personagem, passando pela natureza da personagem e por suas marcas próprias, que estão diretamente ligadas à sua intimidade. Assim ela diferencia-se das demais por seus adjetivos, configurando-se como uma 'qualificação diferencial', no modelo de Yves Reuter (2007), um dos objetivos da análise posteriormente desenvolvida.

Um elemento importante na análise narrativa defendia por Yves Reuter (2007) é o plano de ação da personagem e sua funcionalidade. Com esses dois conceitos emergem a 'distribuição diferencial' da personagem, onde ela aloca em diversos espaços as ações provenientes e formadoras do seu jeito de ser de uma forma mais ou menos estratégica. Em outro nível há a interação entre as personagens, onde cada uma tem o que pode ser chamado de 'autonomia diferencial', pois essas relações só ocorrem dentro dos limites que cada um impõe na distribuição de si mesmo no espaço. Há ainda a 'pré-designação convencional' que conceitua o que é possível uma personagem realizar dentro de um determinado gênero textual e, por fim, o 'comentário explícito' dá nome aquilo que a narradora informa sobre as personagens, categorizando e avaliando sua existência. Contudo, o conceito de 'personagem focalizadora' coloca para o leitor a lente do protagonista, onde esta figura realiza as avaliações principais da narrativa, colocando a realidade sob ótica de sua 'subjetividade' (REUTER, 2007).

As ações de cada personagem só são possíveis em determinados contextos que também balizam as possibilidades de ação que a narrativa apresenta. Porém, os espaços podem ser utilizados como indicadores de como a narrativa poderá ser estruturada, quem é essa personagem e como ele vê o mundo, pois se seleciona os espaços em que ele se encontra, vivencia e reflete sobre suas experiências. Além disso, o tempo também exerce funções semelhantes às do espaço, porém guarda maior peso na historicidade e na fixação da narrativa ao plano do real, ao não-texto, referências ao mundo fora da narrativa, que são parte da cultura, já conhecida antes da elaboração do texto. Assim, o efeito de 'realidade', portanto, é fruto de toda organização textual (REUTER, 2007).

Este artigo propõe-se a refletir sobre como os discursos midiáticos expressam concepções de gênero, podendo reforçar estereótipos do feminino e cristalizar identidades pautadas pelo padrão hierárquico masculinizante vigente, colaborando para a construção da personagem Dilma Rousseff na revista Piauí.

A seção seguinte apresenta as reflexões, aplicação de conceitos e a articulação das categorias de análise. Algumas frases do próprio Diário foram selecionadas para exemplificar o processo analítico. 


\section{Resultados e Discussão}

Apresentar a construção de uma personagem é dar-lhe um sentido que extrapola sua construção textual, vinculandoa a uma atividade de organização estética. Mikhail Bakhtin (2006) aponta que a totalidade de uma personagem só pode ser compreendida com um ponto de apoio fora de si mesma e que este ponto de apoio faça parte de uma consciência criadora, respeitando a singularidade desta personagem. Dessa forma, mesmo que a personagem apresente características estereotipadas, identificar tais pontos é um processo interpretativo que não aponta uma realidade estanque, mas um movimento relacional entre autor (interpretador) e personagem. Mesmo no presente caso, em que, no Diário, Dilma se caracteriza como Yves Reuter (2007) define a uma 'Personagem Focalizadora' - uma vez que abarca todos os eventos presentes nas narrativas. A simples atribuição das características do cotidiano da personagem, apesar de deixar pouca margem para que outros personagens interpretem estas situações, não fecha a relação dialógica estabelecida através da cultura, ao contrário: reforça outros estereótipos polarizados presentes na cultura em relação não apenas à Presidenta, mas a todas as mulheres, na lógica da 'boa mulher' associada ao privado e submisso e ao de 'mulher má', associada ao público e, portanto negativo, competitivo, egoísta, etc. Em outras palavras, mesmo sendo uma personagem centralizadora (tal como costuma acontecer com as personagens chave nesse gênero literário - o diário), exposta a poucas situações de diálogo ou interação discursiva, há margem para a interpretação e posicionamento entre esses polos, de maneira caricata. Como essa interpretação de suas características é baseada nas características 'psicológicas' da personagem, nesse caso não restam muitos elementos para construir uma representação da personagem para além dos estereótipos de gênero já apresentados por Chris Barker (1999).

Já no processo de análise do discurso do corpus do Diário, as frases foram organizadas em quatro grandes categorias. Na primeira, 'estereótipos do feminino', constam características estereotipadas sobre o feminino, permeadas por um plano íntimo da Presidenta no Diário, com colocações acerca de sua vida familiar, paixões platônicas, fixação estética e apreço por telenovelas e seriados. Essa categoria é a que mais enquadra excertos do texto, apontando que os estereótipos são amplamente utilizados como aspecto chave na geração do tom humorístico.

Novela boa essa da Carminha! E a das sete é uma graça! Só gente boa. Aquele Ricardo Tozzi é um gato. A Cláudia Abreu pegou direitinho o jeito da Gaby Amarantos, que eu adoro (Diário da Dilma. Piauí, Fev., 2011, p. 28).

Varri a casa, passei um pano úmido nos móveis e reguei as plantas (Diário da Dilma. Piauí, Fev., 2011, p. 28).

Fiquei grudada na tevê à espera da princesa Kate, mas ela não apareceu. Estranho. Tem tempo que ela não lança uma modinha. Vou ligar para o Cameron (Diário da Dilma. Piauí, Fev., 2011, p. 28).

Ainda que algumas frases se apresentem no contexto político (público), são permeadas por caricaturas da feminilidade e vinculadas a estereótipos do plano privado. O tom satírico presente na caracterização de sua vida pública decorre da suposta inadequação do lugar por ela ocupado, a Presidência da República. Estando culturalmente limitada ao plano privado, a figura feminina no poder causa um estranhamento que, canalizado por vias humorísticas, reproduz as opressões 
hierárquicas de gênero.

'Personalidade da Dilma', a segunda categoria analítica, abarca estereótipos do gênero masculino, relacionados, principalmente, à vida pública de Dilma Rousseff, atribuindo aspectos como truculência e rispidez ao jeito de ser da personagem, associado claramente ao masculino no Diário. Seu passado na luta contra a ditadura também é frequentemente apontado como referência para suas ações e opiniões. Além disso, uma característica marcante desta personagem é a apresentação de certa ignorância do cotidiano institucional da Presidência, que reforça a associação entre o feminino e o âmbito privado como seu 'terreno relacional natural'. Ou seja, ainda que tente subverter as normas desenvolvendo uma postura pública associada ao masculino, suas atitudes reforçam a artificialidade do intento:

Uns setenta generais foram ao palácio me entregar a medalha de grã-mestra da Ordem do Mérito da Defesa do Cacete a Quatro, ou coisa que o valha. Bateram continência direitinho para a subversiva aqui. No discurso, falei que 'o Brasil corrigiu seus caminhos' $e$ nenhum milico triscou. Vou botar a medalha na coleira do Nego (Diário da Dilma. Piauí, Maio, 2011, p. 28).

Vou pedir ao Antonio Patriota que sopre o nome de cada chefe de Estado para o intérprete, que, por sua vez, sussurrará no meu ouvido. Aprendi essa técnica durante a luta armada (Diário da Dilma. Piauí, Fev., 2011, p. 28).

Quando cheguei, todos me esperavam com cara de assustados. Ninguém queria contar do apagão no Nordeste. A Miriam Belchior criou coragem, contou e xinguei até a quarta geração dela (Diário da Dilma. Piauí, Fev., 2011, p. 28).
$\mathrm{Na}$ terceira categoria, 'Política', enquadram-se passagens do texto referentes à vida profissional da Presidenta. Conforme expõe Biroli (2010), o retrato feito de mulheres políticas nas revistas do Brasil demonstra personagens enaltecidas pela valorização da vestimenta e das ocupações referentes ao plano privado de seus lares. $\mathrm{O}$ Diário por vezes apresenta uma personagem aproximada a este modo de ser, enfatizando que suas estratégias seriam conduzidas pelos estereótipos de gênero masculino ou feminino e por suas preferências pessoais, não exatamente pelo contexto político em questão. Assim, os comportamentos podem ser lidos como simbolismos sutis, revelando um formato de atuar nas entrelinhas, que seria atrelado ao feminino, assim como a preocupação com a beleza física.

Vou pedir uma compressa com pepino para desinchar os olhos e descansar um pouco. $O$ Santana disse que o importante é estar bem nas fotos, os acordos são secundários (Diário da Dilma. Piauí, Set., 2011, p. 28).

A gente volta ao Brasil e é tanta chateação, tanto probleminha para resolver. Essa história do Agnelli, que aporrinhação! Um bonitão daquele e eu tive de mandar embora por causa da birrinha do Guido? De inflação, ele não fala lé com cré. Depois eu perco a paciência e ficam dizendo que sou grossa (Diário da Dilma. Piauí, Set., 2011, p. 28).

Hoje tem votação do salário mínimo. Chamei o Temer na minha sala e o fiz sentar no sofá estofado pelo PMDB sergipano. Ele entendeu o recado (Diário da Dilma. Piauí, Março, 2011, p. 28).

'Frases Populares', a quarta categoria, refere-se aos inúmeros 'chavões'

João Gabriel Maracci Silveira Cardoso, João Pedro Cé, Mariana Barcinski e Adolfo Pizzinato 
supostamente ditos por Dilma, compreendidos como uma tentativa de aproximação da personagem ao cotidiano popular, desvinculando-a de solenidades presidenciais. Conforme os pressupostos de Michel Cole (1999), as pessoas utilizam roteiros pré-estabelecidos culturalmente, atestados como senso comum, mas que são fundamentos da organização simbólica e interpretativa da realidade, corroborando na formação e manutenção de estereótipos. $\mathrm{O}$ discurso da personagem apresenta sentimentos e avaliações baseadas neste 'senso comum', revelando que a imagem profissional não necessariamente está vinculada às preferências e gostos pessoais, apontando que, de certa forma, a presidenta é uma pessoa comum, que tem seus desgostos referentes à profissão e que não são necessariamente de cunho técnico e reforçando a representação de intimidade e privacidade como os campos sociais do feminino.

Mas tenho que respeitar os países endividados: em festa de formiga não se elogia tamanduá (Diário da Dilma. Piauí, Dez., 2011, p. 28).

Dia de dormir cedo. Obama e a Michelle chegam às sete e meia da matina. Americano tem mania de fazer tudo cedo. Eles jantam as seis da tarde, pode? Ô gente jeca (Diário da Dilma. Piauí, Abril, 2011, p. 28).

Em casa que mulher manda até o galo canta fino. Tenho de me impor para que a imprensa não derrube todos os ministros (Diário da Dilma. Piauí, Out., 2011, p. 28).

'Estereótipos do feminino' foi a categoria com o maior número de citações enquadradas, 340 (num total de 496), demonstrando que a ferramenta de humor mais utilizada pela coluna é relacionada aos estereótipos de gênero. Compreendido como ferramenta política, o humor divulgado pela revista acaba por disseminar expectativas e opiniões acerca das concepções do feminino embasadas na ideologia da inferioridade da mulher, presentes no senso comum e travestido de refinada crítica política.

As categorias narrativas utilizadas apontam que Dilma é uma personagem cuja 'distribuição diferencial' (locais onde circula) é altamente informal. Apesar de seu exercício como Presidenta, o Diário coloca outra visão sobre o cotidiano da personagem. Não é a ideologia política, as necessidades de mercado ou os movimentos populares e políticos que definem as decisões e alianças da personagem Dilma, mas sim como estes eventos influem nos humores da Presidenta, suas afeições, amizades e, principalmente, o estereótipo de feminino de informalidade, de 'privacidade'. Os locais onde circula são avaliados através de gostos pessoais, retirando o cunho profissional do exercício de Estado e o uso de ditos populares pode ser um indicativo desta banalização. As estratégias utilizadas para realização de alianças políticas e lidar com as situações críticas é permeada por posturas que podem ser vistas como antagônicas, mas fazendo parte da mesma personagem. Dessa forma, as posturas tomadas no espaço explicitamente público são calcadas nos estereótipos do masculino (hostilidade, truculência, resolutividade) e as reflexões que constroem a narrativa íntima da personagem são atravessadas por estereótipos do feminino (passividade, fragilidade, futilidade).

Essas proposições constroem não só o espaço funcional da personagem. Está exposta aqui também a 'qualificação diferencial' que a personagem Dilma possui no Diário. Uma mulher que, ao mesmo tempo, carrega o masculino e o feminino em sua caracterização, ainda que estas ações pareçam não pertencer à mesma identidade, 
já que se articula em espaços diferenciados.

Dentro desta instância particular da personagem, podemos articular as quatro categorias, que revelam um contraste entre a postura impositiva e os estereótipos do feminino apresentados em diferentes situações. Desta forma, percebe-se que um grande número de citações pode ser enquadrado em diferentes categorias, explicando por que as referências à política ora apresentam-se permeadas por estereótipos do feminino, ora do masculino. As ambivalências na construção da personagem referem-se, principalmente, ao caráter binário da segregação de gênero (ABOIM, 2012), relacionando-a a padrões estereotipados de feminilidade e masculinidade, colocados sempre em oposição, como podemos ver em:

Sabe que eu acho esse cara da FIFA que vem me atormentar a vida, esse tal de Volker, um morcegão? Coisa fina! Infelizmente não posso deixar aflorar minha porção mulher... é preciso ser firme, do contrário eles conseguem emplacar entrada dupla para gestantes (Diário da Dilma. Piauí, Out., 2011, p. 28).

Acordei com a pá virada e pedi uma reunião urgente com esse pessoal do DNIT. Olhei no olho de cada um deles e parti pra ofensiva: 'Vocês são moleques, moleques!' Dei um soco na mesa, pedi um absinto sem gelo e virei de um gole só. Antes de sair batendo a porta, peguei o Juvenal Nascimento pela gola e soltei: 'serei o teu pior pesadelo!' Só depois me lembrei de que o nome dele é Alcides. Dane-se! ('Diário da Dilma'. Piauí, Ago., 2012, p. 28).

O Wagner Rossi pediu demissão? Isso ninguém me avisa. Era ele o do Turismo? Cedi à pressão política e participei de mais uma reunião para ouvir reclamações sobre a faxina, algemas, blá-blá-blá. Vem cá, esse pessoal não trabalha, não? Passados dois minutos de rame-rame, cravei os olhos no meu iPad. Passei o resto do tempo assistindo à terceira temporada de Sex and the City. Gosto muito dessa Samantha ('Diário da Dilma'. Piauí, Ago., 2012, p.

João Gabriel Maracci Silveira Cardoso, João Pedro Cé, Mariana Barcinski e Adolfo Pizzinato 


\section{Considerações Finais}

A presente análise encerra-se sobre o modo de narrativa empregado no Diário da Dilma e, nesse caso, a revelação da intimidade de uma personagem nos coloca como leitores de confissões e acompanhantes de seu cotidiano. Para além da superficialidade, entramos num local, um verdadeiro mundo de interpretações, revelando o caráter heterogêneo da realidade desta personagem - identidades múltiplas que contribuem para que uma pessoa veja os diferentes eventos sobre diversas óticas, criando, assim, a intimidade, a vida pública, a mulher apaixonada, a avaliação informal das relações institucionais - apesar de apenas uma mulher reunir todos estes aspectos. Assim, as categorias criadas apenas separam aspectos da mesma figura, que não pode ser compreendida olhando apenas para estas compartimentações como facetas separáveis, devendo ser considerada como um ente dinâmico e relacional.

A multiplicidade emerge de uma personagem criada (como qualquer outra) a partir de outro sujeito (autor), colocado no mundo e orientado pelo que o próprio autor considera passível de existir para aquele sujeito, revelando, portanto, não só sua concepção de personagem, e a representação cômica da Presidenta Dilma, mas também um posicionamento frente a esta mesma figura pública. Sendo assim, há o estabelecimento de um movimento que não tem um início em um ponto específico de sua trajetória 'real', mas tem sua criação quando um diálogo com a personagem é estabelecido. A virtualização de outro sujeito permite a criação desse diálogo, nos aponta para o surgimento de possibilidades do feminino que o GhostWriter do Diário da Dilma cria, já que a sua imaginação atua como o ponto para 0 surgimento dessa entidade. Aponta-se que este imaginário é permeado por orientações misóginas, que apontamos ainda serem presentes na cultura, e na apresentação das mulheres na mídia tal como apontam Barker (1999), Biroli, (2011; 2010), Biroli e Mello (2010). Assim, revela-se que a individualidade desta personagem em seu diário guarda uma realidade própria, permeada por questões que vão de um seio emocional até um plano cultural.

Apresentamos uma análise sobre a reprodução dos mecanismos de opressão de gênero que podem parecer velados, mas encontram-se nas entrelinhas da expressão literária. Como exposto acima, o humor acaba por manter os padrões estereotipados da representação da identidade feminina na vida política, mantendo estruturas machistas de identificação de gênero em relação à personagem aqui analisada.

This is a literal translation of a Brazilian proverb. The proverb refers to women's power when heading homes, keeping children and men under their control.

\section{Referências}

ABOIM, Sofia. 'Do público e do privado: uma perspectiva de género sobre uma dicotomia moderna'. Estudos Feministas, v. 20, n. 1, p. 95-117, 2012.

BAKHTIN, Mikhail. Estética de la creación Verbal. $2^{\mathrm{a}}$ edição. Siglo Veintiuno: Buenos Aires, 2008.

BARKER, Chris. Televisión, globalización e identidades culturales. $1^{\text {a }}$ edição. Barcelona: Paidós Comunicación, 1999.

BIROLI, Flávia. 'Mídia, tipificação e exercícios de poder'. Revista Brasileira de Ciência Política, n. 6, p. 71 - 98, 2011. 
BIROLI, Flávia. 'Gênero e política no noticiário das revistas semanais brasileiras: ausências e estereótipos'. Cadernos Pagu, n. 34, p. 269 - 299, 2010.

BIROLI, Flávia; MELLO, Janine. 'Gênero e política: hipóteses sobre as diferenças entre a atuação de deputadas e deputados federais na 52 $2^{\text {a }}$ legislatura (2003-2006). Revista Ártemis, v. 11, p. 1 - 20, 2010.

BRUNER, Jerome. Atos de significação. Porto Alegre: Artmed, 1997.

BOHN, Simone. 'Mulher para presidente do Brasil? Gênero e política na perspectiva do eleitor brasileiro'. Revista Opinião Pública, v. 14, n. 2, p. 352 - 379, 2008.

CASTELLS, Manuel. O poder da identidade. São Paulo: Paz e Terra, 1999.

COLE, Michael. Psicología Cultural: Una disciplina del pasado y del futuro. Madrid: Ediciones Morata, 1999.

COLLING, Ana. A construção histórica do feminino e do masculino. In: STREY, Marlene Neves (et al). Gênero e cultura: questões contemporâneas, Porto Alegre, EDIPUCRS, 2004, p. $13-38$.

FINAMORE, Claudia Maria. Mulheres candidatas: relações entre gênero, mídia e discurso. Estudos Feministas, v. 14, n. 2, p. 347 - 362, 2006.

NEUHOUSER, Kevin. Sources of women's power and status among the urban poor in contemporary Brazil. Signs, v. 14, n. 3, p. 685 - 702, 1989.

REUTER, Yves. Análise de narrativa: O texto, a ficção e a narração. $2^{\mathrm{a}}$ edição. Rio de Janeiro: Difel, 2007.

PRADO, Marco Aurélio Máximo. Da mobilidade social à construção da identidade política: reflexões em torno dos aspectos psicossociais das ações coletivas. Psicologia em Revista, v.8, n. 11, p. 59 - 67, 2002.

SOUZA, Juliana Lopes de Almeida; LIGÓRIO, Claudia Alice de. Jornalismo literário: o ritual da revista piauí. Revista Brasileira de Ensino de Jornalismo, v.1, n.9, p. 143 - 172, 2012.

STREY, Marlene. Gênero. In: STREY, Marlene (Et al). Psicologia social contemporânea. $\quad 5^{\text {a }}$ edição. Petrópolis: Editora Vozes, 2001, p. 181-199.

TAJFEL, Henry. Human Groups and Social Categories. Cambridge: Cambridge University Press, 1981.

VAN DIJK, Teun. Discurso e Poder. São Paulo: Contexto, 2010.

WOITOWICZ, Karina Janz. O riso como lugar de expressão e fortalecimento do machismo. Revista Internacional de Folkcomunicação, v.1, p. 1 - 16, 2009.

Recebido em 16 de outubro de 2013. Aceito em 20 de dezembro de 2013. 